\title{
Mechanism-based modeling of time-varying magnetic fields effects on cortical activity
}

\author{
Julien Modolo ${ }^{1,2,3^{*}}$, Alex W Thomas ${ }^{1,2,3}$, Alexandre Legros ${ }^{1,2,3,4}$ \\ From The Twenty Third Annual Computational Neuroscience Meeting: CNS*2014 \\ Québec City, Canada. 26-31 July 2014
}

\section{Background}

Understanding how extremely low-frequency (ELF, < $300 \mathrm{~Hz}$ ) magnetic fields (MF) interact with human brain activity is an important question, especially regarding potential effects of power-lines MF $(60 \mathrm{~Hz}$ in North America). Such knowledge is critical to 1) contribute to guidelines protecting public and workers from exposure to ELF MFs [1,2]; and 2) design novel non-invasive brain stimulation techniques using ELF MFs to interfere with pathological brain activity patterns.

\section{Methods}

We used an extensively validated neural mass model [3] describing the main neuronal populations forming a cortical column, which we extended by including 1 ) a time-dependent membrane potential perturbation caused by the induced electric field; 2) a model linking post-synaptic calcium concentration and synaptic plasticity processes [4]. We used increasing levels of MF flux density at $60 \mathrm{~Hz}$ to identify the threshold for significant effects on simulated EEG alpha $(8-12 \mathrm{~Hz})$ power. A

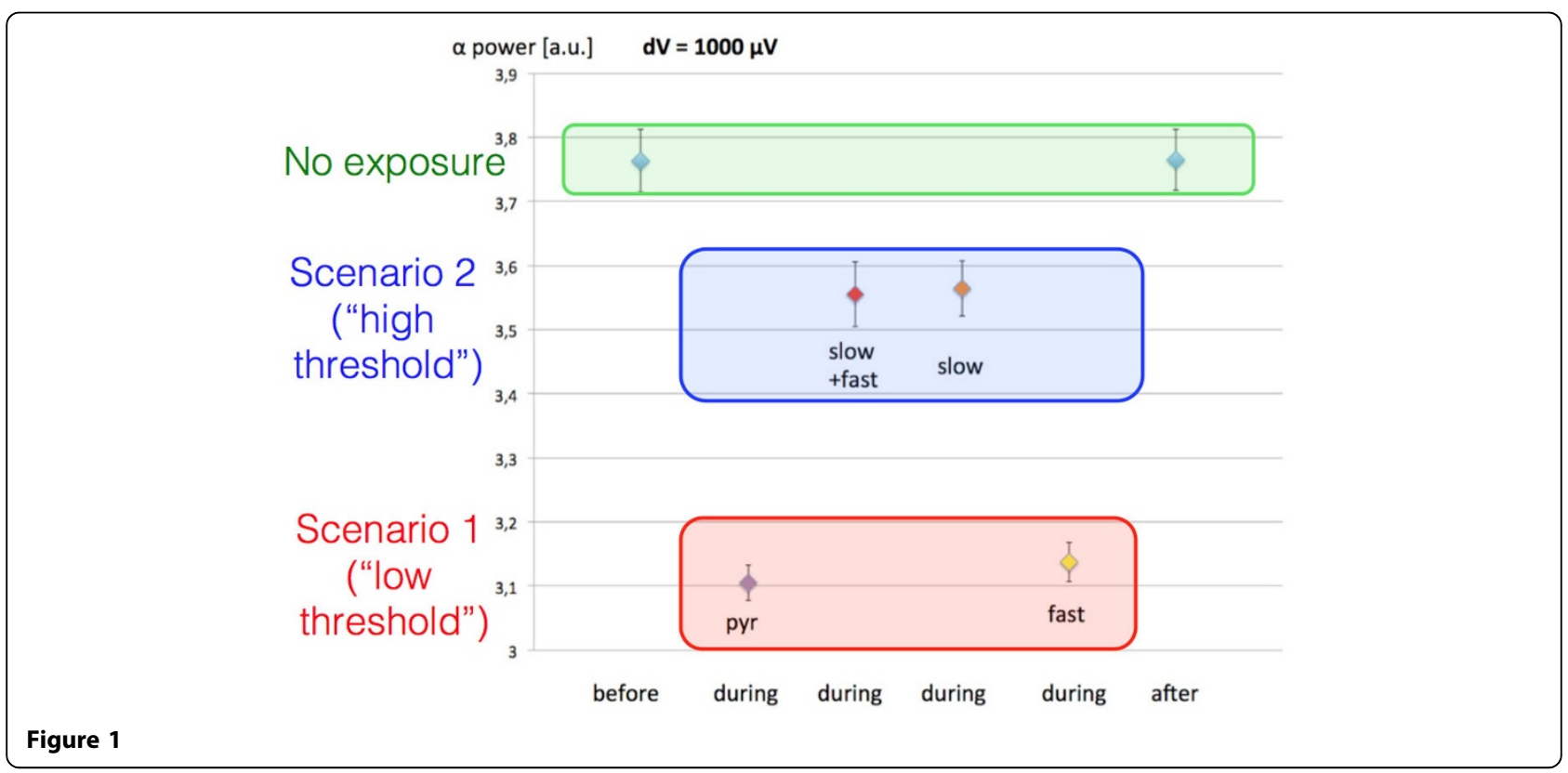

\footnotetext{
* Correspondence: jmodolo@lawsonimaging.ca

${ }^{1}$ Human Threshold Research Group, Lawson Health Research Institute,

London, ON, N6A4V2, Canada

Full list of author information is available at the end of the article
} 
4x3x2 ANOVA for repeated measured measures was conducted on EEG alpha power before/during/after exposure, with/without $60 \mathrm{~Hz}$ MF exposure, with/without synaptic plasticity.

\section{Results}

Simulated EEG alpha power decreased with increased $60 \mathrm{~Hz}$ MF flux density (significant for $250<\mathrm{dV}<500 \mu \mathrm{V}$ when only pyramidal neurons were modulated), without significant effects from synaptic plasticity processes. If slow inhibitory interneurons [3] were also modulated, EEG alpha power decrease due to MF exposure was significantly diminished (see Figure).

\section{Conclusions}

The model will be used to 1) understand human data currently acquired in our group [5]; and 2) study in silico effects of transcranial alternating current stimulation and magnetic stimulation (tACS/TMS). Future work will include frequency-dependent effects from extracellular medium dielectric properties, and selective modulation of specific neuronal populations.

\section{Acknowledgements}

Lawson Health Research Institute, Mitacs Elevate Program, Hydro-Québec/ Electricité de France/Réseau de Transport d'Electricité, and Canadian Institutes of Health Research.

\section{Authors' details}

${ }^{1}$ Human Threshold Research Group, Lawson Health Research Institute, London, ON, N6A4V2, Canada. 'Department of Medical Biophysics, Western University, London, ON, Canada. ${ }^{3}$ Department of Medical Imaging, Western University, London, ON, Canada. ${ }^{4}$ School of Kinesiology, Western University, London, ON, Canada.

Published: 21 July 2014

\section{References}

1. ICNIRP: Guidelines for limiting exposure to time-varying electric and magnetic fields (1 Hz to $100 \mathrm{kHz}$ ). Health Phys 2010, 99(6):818-836

2. IEEE: C95.6 - IEEE standard for safety levels with respect to human exposure to electromagnetic fields, 0-3 kHz. IEEE New York; 2002.

3. Wendling F, Bartolomei F, Bellanger JJ, Chauvel P: Epileptic fast activity can be explained by a model of impaired GABAergic dendritic inhibition. Eur J Neurosci 2005, 22:343-356.

4. Shouval HZ, Castellani GC, Blais BS, Yeung LC, Cooper LN: Converging evidence for a simplified biophysical model of synaptic plasticity. Bio Cybern 2002, 87:383-391.

5. Legros A, Modolo J, Goulet D, Plante M, Souques M, Deschamps F, Ostigui G, Mezei G, Lambrozo J, Thomas AW: Magnetophophene perception and associated neurophysiological responses of the human central nervous system exposed to 50 and $60 \mathrm{~Hz}$ magnetic fields of up to $50 \mathrm{mT}$. CIGRE EMF International colloquium 2013.

doi:10.1186/1471-2202-15-S1-P116

Cite this article as: Modolo et al:: Mechanism-based modeling of timevarying magnetic fields effects on cortical activity. BMC Neuroscience 2014 15(Suppl 1):P116.

\section{Submit your next manuscript to BioMed Central and take full advantage of:}

- Convenient online submission

- Thorough peer review

- No space constraints or color figure charges

- Immediate publication on acceptance

- Inclusion in PubMed, CAS, Scopus and Google Scholar

- Research which is freely available for redistribution

Submit your manuscript at www.biomedcentral.com/submit
C Biomed Central 